\title{
Glucogenic supply increases ovulation rate by modifying follicle recruitment and subsequent development of preovulatory follicles without effects on ghrelin secretion
}

\author{
C Letelier ${ }^{1,2,3}, \mathrm{~F} \mathrm{Mallo}^{3}$, T Encinas ${ }^{4}, \mathrm{~J} \mathrm{M}$ Ros $^{4}$ and A Gonzalez-Bulnes ${ }^{1,4}$ \\ ${ }^{1}$ Departamento de Reproducción Animal, INIA, 28040 Madrid, Spain, ${ }^{2}$ Instituto de Ciencia Animal y Tecnología de \\ Carnes, Universidad Austral de Chile, Casilla 567, Valdivia, Chile, ${ }^{3}$ Departamento de Biología Funcional y Ciencias \\ de la Salud, Universidad de Vigo, 36310 Vigo, Spain and ${ }^{4}$ Departamento de Toxicología y Farmacología, Universidad \\ Complutense de Madrid, 28040 Madrid, Spain
}

Correspondence should be addressed to C Letelier who is now at Facultad de Ciencias Veterinarias, Universidad Austral de Chile, Campus Isla Teja s/n, Casilla 567, Valdivia, Chile; Email: claudialetelier@uach.cl

\begin{abstract}
This study determined the effects of short-term energy inputs on ghrelin secretion and possible links with changes in the follicle population or the ovulation rate. Oestrous cycle was synchronized in 16 Manchega sheep using progestagen sponges and cloprostenol. Half of the animals were treated from days 0 to 4 by the oral administration, twice daily, of 200 ml of a glucogenic mixture containing $\mathbf{7 0} \%$ of glycerol, $20 \%$ of 1,2-propanediol and $10 \%$ of water; the control group received $200 \mathrm{ml}$ water. The mean ( \pm s.E.M.) plasma glucose increased immediately after the first administration $(3.9 \pm 0.3 \mathrm{vs} 3.0 \pm 0.1 \mathrm{mmol} / \mathrm{l}$ in control group, $P<0.05)$, remaining statistically different during the treatment. However, plasma ghrelin levels were similar in both groups. On the other hand, the results indicated that short-term energy inputs modify ovulation rate $(1.9 \pm 0.1$ vs $1.3 \pm 0.2$ in control group, $P<0.05)$ by increasing the number of follicles able to be selected to ovulate during the period of treatment ( $\geq 4 \mathrm{~mm}$ in size; $5.9 \pm 0.6$ vs $4.3 \pm 0.4$ at day $2, P<0.05$ ). After sponge withdrawal, the number of these follicles decreased throughout follicular phase $(5.8 \pm 0.8$ to $1.5 \pm 0.4, P<0.0005)$ while the number of large follicles increased ( $\geq 6 \mathrm{~mm}$ in size; $0.8 \pm 0.4$ to $2.0 \pm 0.3, P<0.05$ ); this would indicate an active growth of preovulatory follicles that were not found in the control group. Thus, the increases of ovulation rate by high-energy inputs would be caused by an enhancement in the developmental competence of preovulatory follicles.

Reproduction (2008) 136 65-72
\end{abstract}

\section{Introduction}

Nutrition is a major factor influencing reproductive success (O'Callaghan et al. 2000, Webb et al. 2004). Most of the studies on this area have been conducted in sheep and have shown that, in the female, both overfeeding and underfeeding affect the ovulatory processes, the quality of oocytes and early embryos, the development of the foetus and the viability of newborns (Martin et al. 2004). Nutrition influences may be obtained through changes in body weight and condition, either in a long-term ('static effect', in which heavy females have higher ovulation rates) or in a shortterm changes ('dynamic effect', by a higher feeding over 3-4 weeks before mating; Smith \& Stewart 1990, Scaramuzzi et al. 2006). However, reproductive features may be also improved by supplying nutritional inputs in a very short period of time, less than 10 days, without changing body weight and condition (concept named as 'focus feeding' by Martin et al. 2004).
Focus feeding may be applied for enhancement of ovarian activity during the follicular phase, increasing the number and quality of ovulations (Munoz-Gutierrez et al. 2002, Vinoles et al. 2005). In brief, a supplementation for 4-6 days around timing of preovulatory follicle selection increases the ovulation rate over $20-30 \%$, without changes in body weight (Scaramuzzi et al. 2006). This effect, termed 'immediate nutrient effect' or 'acute effect', was firstly described to be obtained by supplementing with lupin grains ('lupin effect'; Stewart \& Oldham 1986, Teleni et al. 1989). Thereafter, numerous studies have reported the positive energy balance of short-term nutritional protocols with energy-yielding nutrients, such as lupin grain (Rowe \& Ferguson 1986, Smith \& Stewart 1990, Pearse et al. 1994, Williams et al. 2001, Munoz-Gutierrez et al. 2002, 2004), corn grain (Landau et al. 1995, 1996, Letelier et al. 2008), infusion of nutrients, like amino acids and glucose (Teleni et al. 1989, Downing et al. 1995, Landau et al. 1996, RodríguezIglesias et al. 1996, Rubio et al. 1997, Munoz-Gutierrez 
et al. 2002, 2004) and metabolic hormones (insulin; Hinch \& Roelofs 1986).

These changes in energy balance would affect the ovary directly, being associated with increased folliculogenesis and ovulation rate (Scaramuzzi et al. 2006). In fact, ovulation rate is increased by the administration of glucose and other energy-yielding substrates (glucogenic mixtures), either intravenously (Downing et al. 1995, Munoz-Gutierrez et al. 2002, 2004), intraperitoneally (Rubio et al. 1997), orally (Rodríguez-lglesias et al. 1996, Williams et al. 2001) or infused into the abomasum (Landau et al. 1995). Changes in folliculogenesis have been described to be consisting of an increase in the number of follicles larger than $3.5 \mathrm{~mm}$, but without any effects on the number of smaller follicles (MunozGutierrez et al. 2002). Although Vinoles et al. (2005) found that the number of ovulatory follicles (OFs) would be increased, ovulation rate remained unaffected.

However, there is a lack of information on the effects of focus feeding on follicular dynamics during the preovulatory wave, as highlighted in the review of Scaramuzzi et al. (2006). The present study was developed shortly before the edition of such review. Coincidentally with the considerations of that review, the first objective of this study was to determine, by a serial real-time ultrasonographic study, the effects of a short treatment with a glucogenic mixture administered orally (as previously described by Williams et al. 2001), on the follicle population and activity during the administration of the treatment and during the subsequent follicular phase for determining any relationship with possible changes in ovulation rate.

The immediate nutrient effect seems to be related to the large amounts of digestible energy that are provided, causing a high increase in plasma insulin and glucose (Williams et al. 2001, Munoz-Gutierrez et al. 2002, 2004). Several studies were focused in identifying the factor signalling nutritional effects on reproduction (Gong 2002, Armstrong et al. 2003, Hess et al. 2005). Infusions of insulin increased the ovulation rate of ewes (Hinch \& Roelofs 1986, Downing et al. 1995), suggesting a direct ovarian action of insulin later confirmed by studies of follicle dynamics (Hess et al. 2005). Leptin has also been proposed to have an important signalling function in the reproductive system (Boland et al. 2001, Spicer 2001), since influences both glucose homeostasis and insulin effects (Cunningham et al. 1999, Marie et al. 2001). Vinoles et al. (2005) found that increases in circulating concentrations of glucose, insulin or leptin positively correlate with the follicle development and ovulation rate and proposed a direct effect at the ovarian level. However, such a relationship has still not been proven, which may imply the involvement of other factors (insulin-like growth factor and ghrelin among others).

Ghrelin is a novel factor involved in the control of energy balance and metabolism (Truett \& Parks 2005); Ghrelin actively regulates feeding in domestic animals
(Hayashida 2001), its secretion being increased on fasting periods and decreased after feeding (Sugino et al. 2004). There is also evidence that ghrelin is involved in reproductive function (Gaytan et al. 2003, Barreiro \& Tena-Sempere 2004, Miller et al. 2005, Tena-Sempere 2005, García et al. 2007). Ruminant species also seem to utilize the ghrelin system to modulate endocrine and metabolic responses to nutrition and energy balance (Harrison et al. 2007); however, little is known about its link with reproductive processes in these species. The data so far available strongly suggest that, through local and/or systemic mechanisms, ghrelin operates by integrating control of energy balance and reproduction (Tena-Sempere 2005). Therefore, the second objective of this study was to assess the effects of the glucogenic treatment on plasma circulating levels of ghrelin linked to ovarian function.

\section{Results}

\section{Effects of energetic supplementation on oestrus and ovulatory activity}

The infusion of the glucogenic mixture had no effects on the onset of oestrus activity, but caused a significant increase in the ovulation rate $(1.9 \pm 0.1$ vs $1.3 \pm 0.2$, $P<0.05)$; the luteal function being adequate in both groups $(2.8 \pm 0.3$ vs $2.6 \pm 0.2 \mathrm{ng} / \mathrm{ml}$ of progesterone in control sheep). This acute effect was preceded by changes in metabolic status and follicle dynamics.

\section{Effects of energetic supplementation on metabolic status}

The supply of the glycogenic compound immediately increased the plasma glucose levels after the first day administration $(3.9 \pm 0.3$ in treated versus $3.0 \pm 0.1 \mathrm{mmol} / \mathrm{l}$ in control group, $P<0.05$; Fig. 1A). These differences remained at statistically significant levels throughout the treatment. Postprandial ghrelin levels were similar in groups, remaining between 30 and $45 \mathrm{pg} / \mathrm{ml}$ during the treatment period (Fig. 1B).

\section{Follicle dynamics and function throughout the glucogenic treatment}

The infusion of the glucogenic mixture caused a significant increase $(P<0.05)$ in the number of total follicles $\geq 2 \mathrm{~mm}$ in size from values similar to found in control ewes prior to the treatment (mean number of $17.5 \pm 1.3$ for control versus $15.6 \pm 1.4$ in treated sheep, NS; Fig. $2 \mathrm{~A}$ ). Thus, mean number of $\geq 2 \mathrm{~mm}$ follicles was higher in treated group between days 1 and $4(23.7 \pm 1.7$ vs $19.5 \pm 1.8$ respectively; $P<0.005)$. The same was observed when considering the number of follicles able to be selected to ovulate ( $\geq 4 \mathrm{~mm}$ follicles in size, Fig. $2 \mathrm{~B}$ ). The mean number was similar between treated and control sheep 

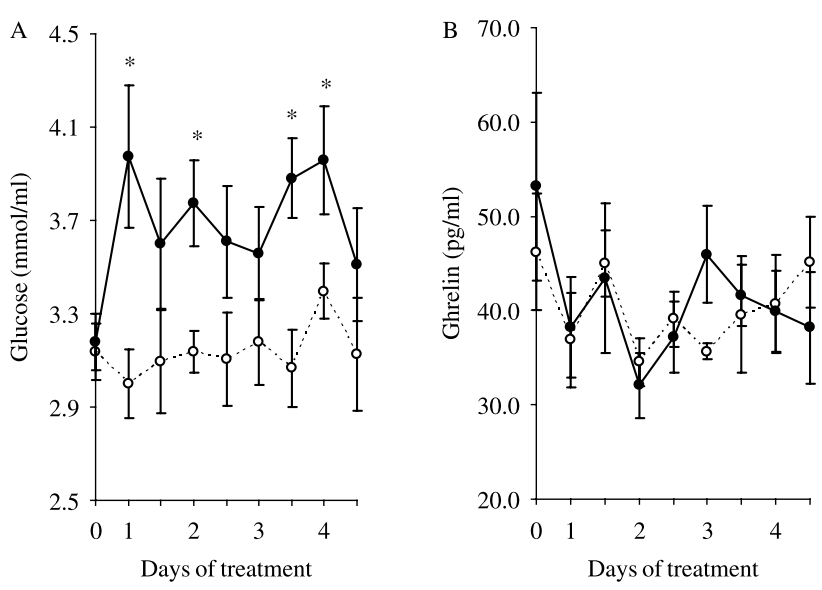

Figure 1 Plasma concentration (mean \pm S.E.M.) of (A) glucose and (B) ghrelin in sheep that received a short-term energy input (continuous line, black circles) for 5 days, and in ewes at maintenance levels (dashed line, open circles). Siginificant differences between values are indicated by $*, P<0.05$.

in the days prior treatment $(4.1 \pm 0.2$ for control versus $3.8 \pm 0.2$ in treated sheep, NS) and increased thereafter to be higher during days $1-4(4.6 \pm 0.3$ for treated versus $3.9 \pm 0.1$ in control group, $P<0.05)$.

\section{Follicle dynamics and function during the subsequent follicular phase}

There were significant differences between treated and non-treated groups in the patterns of follicular development after stopping glucogenic infusion and sponge removal (Fig. 3). The evolution profile of the number of smaller follicles (2-3 $\mathrm{mm}$ in size) was similar between groups; however, the developmental pattern of medium (4-5 mm; able to be selected to ovulate) and large follicles ( $\geq 6 \mathrm{~mm}$, ovulatory size) were different. Both categories remained stable in control group $(2.4 \pm 0.4$ to $2.7 \pm 0.6$ for medium and $1.8 \pm 0.5$ to $1.9 \pm 0.3$ for large follicles). In treated sheep, the number of medium follicles decreased throughout follicular phase $(5.8 \pm 0.8$ to $1.5 \pm 0.4, P<0.001)$, while the number of large
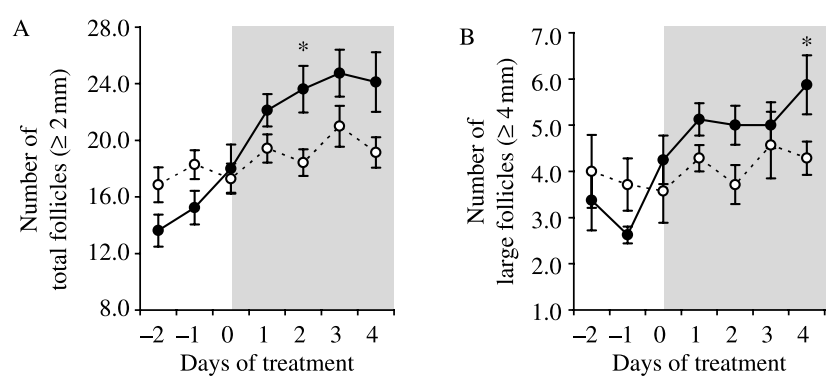

Figure 2 Mean number ( \pm s.E.M.) of follicles with $(\mathrm{A}) \geq 2 \mathrm{~mm}$ and (B) $\geq 4 \mathrm{~mm}$ in size in sheep that received a short-term energy input (continuous line, black circles) for 5 days (shaded area), and in ewes at maintenance levels (dashed line, open circles). Siginificant differences between values are indicated by *.
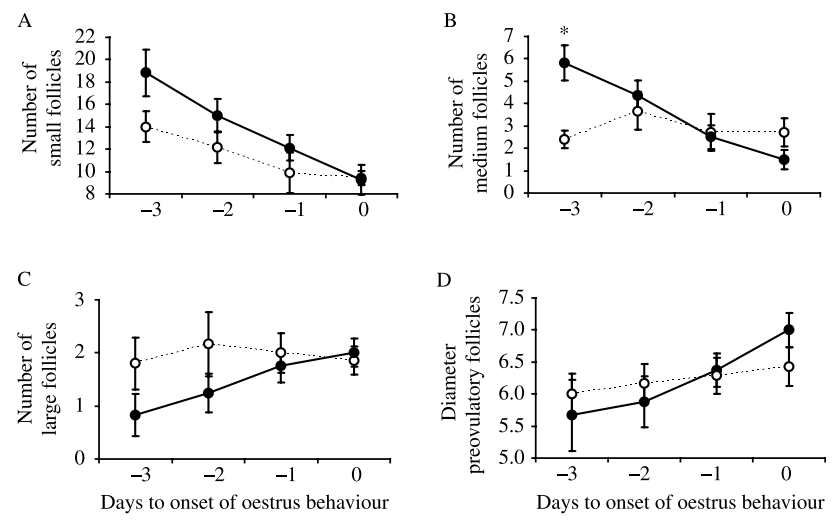

Figure 3 Mean number ( \pm s.E.M.) of follicles with (A) 2-3 mm,

(B) $\geq 4 \mathrm{~mm}$ and (C) $\geq 6 \mathrm{~mm}$ in size, and (D) mean diameter ( \pm s.E.M.) of preovulatory follicles during the follicular phase (day $0=$ day of oestrus) in sheep that received a short-term energy input (continuous line, black circles) and in ewes at maintenance levels (dashed line, open circles). Significant differences between values are indicated by *

follicles increased $(0.8 \pm 0.4$ to $2.0 \pm 0.3, P<0.05)$, which would indicate an active growth to preovulatory sizes of some of the medium follicles. This is confirmed by the fact that the diameter of the largest follicle (LF1) increased through the follicular phase in the treated (5.6 \pm 0.6 to $7.0 \pm 0.3, P<0.05)$, but not in the control group (Fig. 3D). There were no differences in oestradiol secretion at oestrus day, although tended to be lower in control group $(3.5 \pm 0.5$ vs $4.1 \pm 0.4 \mathrm{pg} / \mathrm{ml})$. Coincidentally, the effects of large follicles on turnover of remaining follicles were similar between groups, although the number of regressing follicles tended to be higher in treated sheep (Fig. 4).

The efficiency of the large follicles to ovulate was higher in treated than in control sheep. Ninety-two percent of follicles $\geq 6 \mathrm{~mm}$ in size ovulated in the treated group, while $74 \%$ ovulated in the control group; differences were even higher when considering follicles $\geq 5 \mathrm{~mm}$ (96\% in treated versus $60 \%$ in control group). The analysis of the individual development of OFs showed that all of them, both in treated and untreated sheep, arose from antral follicles present in the ovary at the time when the sponge was removed; the size being larger in control sheep $(6.3 \pm 1.1 \mathrm{vs} 5.2 \pm 0.4 \mathrm{~mm})$, although differences were not found to be significant due to a high variability. Thus, 7 out of 15 of OFs in treated animals were $4 \mathrm{~mm}$ in size at sponge withdrawal $(46.6 \%)$; this was caused by the smaller size of the second OF (OF2) in sheep with double ovulations $(6.3 \pm 0.5$ for OF1 and $4.3 \pm 0.3$ for OF2). Thereafter, the diameter of OF1 remained stable while OF2 increased during the follicular phase $(P<0.001, r=0.869)$; OF2 increased a mean of $2.6 \pm 0.4 \mathrm{~mm}(P<0.001)$, thus the final size was similar to OF1. In control group, OFs remained stable and, therefore, the overall mean size of OFs was similar between groups $(6.5 \pm 0.2$ in treated and $6.4 \pm 0.3$ in control ewes). 

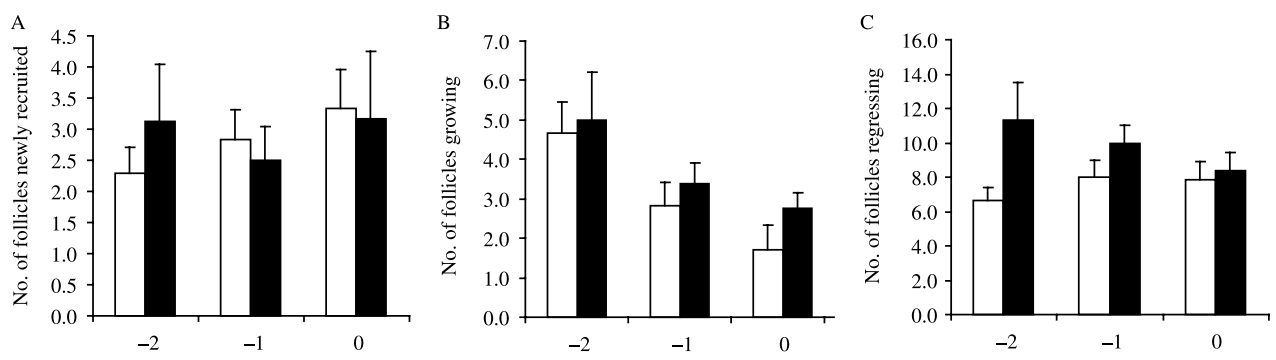

Figure 4 Mean number ( \pm S.E.M.) of (A) follicles newly recruited, (B) growing in size and (C) regressing in size during the follicular phase (day $0=$ day of oestrus) in sheep that received a short-term energy input (black bars) and in ewes at maintenance levels (white bars).

\section{Discussion}

The results of the present study indicate that short-term energy inputs modify ovulation rate by increasing both number and, which is more important, developmental competence (in terms of ovulatory efficiency) of ovarian follicles.

The immediate effect of nutrition is associated with an increase in ovulation rate (Scaramuzzi et al. 2006); however, the results are not consistent between authors (Stewart 1990, Williams et al. 2001, Vinoles et al. 2005) and very few studies report significant differences in ovulation rate; possible causes of differences may be related to the fact that ovulation rate is a discontinuous variable (Lindsay et al. 1993, Vinoles 2003). It is largely known that ovulation rate in sheep can be increased, at ovarian level, by a higher recruitment of follicles or a lower rate of atresia (Driancourt et al. 1990, Scaramuzzi et al. 1993). In the present study, the supply of energy increased recruitment of follicles, similar to that reported in previous studies in heifers (Gutierrez et al. 1997). The number of follicles entering in the terminal growth phase increased in response to the supply of the glucogenic mixture from the very first administration; such an increase was detected both when considering the number of total $\geq 2 \mathrm{~mm}$ follicles and when considering separately follicles with $2-3 \mathrm{~mm}$ and follicles $\geq 4 \mathrm{~mm}$; which is opposite to the previously reported absence of effects on the number of smaller follicles (Munoz-Gutierrez 2005). Differences between both studies may be related by different effects of the protocol and the stimulus used. The other finding to be highlighted when analyzing the present results is the sharp increase in the number of follicles in response to the first glucogenic doses, while tending, to stabilize thereafter, thus allowing a reduction in the number of doses. Such action would facilitate the applicability of treatment, and even would improve the results by avoiding waste and ageing of follicles prior to sponge removal.

In the present study, both the number of small $(2-3 \mathrm{~mm}$ in size) and the number of medium follicles $(4-5 \mathrm{~mm}$ in size) were higher in treated sheep at sponge removal; conversely, the number of $\geq 6 \mathrm{~mm}$ follicles was lower than in control ewes. Thereafter, during the follicular phase of control sheep, the patterns and features of follicular development were similar to previously described for Manchega breed (Gonzalez-Anover et al. 2006). However, in treated sheep, there was an active growth of the follicles to larger sizes. Thus, the number of OFs was the same in control and treated sheep at the onset of oestrus behaviour, which is again different to previously described (Vinoles et al. 2005) and, again, it would be necessary to elucidate possible causes of such differences. However, although the number of preovulatory, and even non-ovulatory, follicles was the same, the ovulation rate was finally higher in treated sheep. If the number of preovulatory follicles is the same, the difference may be related to a higher chance to ovulate of the follicles in the treated group. In fact, the data indicate that most of the preovulatory follicles in control sheep are in the static phase while treated females have most of their follicles in the growing phase.

The presence of OFs in the growing phase in sheep has been related to increased ability to ovulate and higher fertility when ovulating (Ungerfeld \& Rubianes 1999, Vinoles etal. 1999). Thus, overall, the present data indicate that the higher ovulation rate found in treated sheep may be related to an increased developmental competence of their follicles. Whether this effect may affect not only follicular growth and ovulation (Webb et al. 2004) but also oocyte quality (Armstrong et al. 2003) and fertility could not be elucidated in the present trial, but arises as an objective for further studies. Other possible objectives for studies in the near future may be related to effects of glycogenic supplementation on patterns of follicle-stimulating hormone (FSH) and/or luteinizing hormone (LH) secretion. Both FSH and $\mathrm{LH}$ have a key role in the final development of large estrogenic follicles to ovulation. In the well-known model of Scaramuzzi et al. (1993) in sheep, an increase in ovulation rate would depend on either an increased gonadotrophin-responsive follicle pool or an extended period of $\mathrm{FSH}$-induced growth prior to the pre-ovulatory LH surge. Studies comparing control sheep and animals food supplemented for a long time indicated that the main cause of increased ovulation rate is related to higher $\mathrm{FSH}$ levels, which promote the recruitment of a higher number of gonadotrophin-responsive follicles during an extended period of OF recruitment (Vinoles et al. 2002). The role of 
nutrition on LH pulsatility remain to be elucidated, although the results of different studies indicate a lack of effects on $\mathrm{LH}$ secretion.

The second objective of this study was to assess the effects of the glucogenic treatment on plasma concentration of ghrelin and possible links with ovarian activity. Ghrelin has a role in the regulation of glucose in ruminants (Takahashi et al. 2006) but, in the present study, there were no significant differences in ghrelin secretion between groups although there was a sharp increase in glucose levels. The results showed a higher, although nonsignificant, decrease in plasma ghrelin levels in treated sheep, which could be related to the fact that ghrelin concentrations are described to show an immediate decrease after feeding (Sugino et al. 2004, Takahashi et al. 2006, Wertz-Lutz et al. 2006). Statistical analysis was not able to establish any relationship between differences in ovarian activity and plasma ghrelin levels.

The possible causes of the lack of differences and effects in the present study may be related to the fact that energy balance is regulated by multiple pathways in ruminants that use strategic opportunities from the energy point of view to adapt to the environment, affecting short-term reproduction (Martin et al. 2004). This fact hinders efforts for unveiling links between energy balance and reproduction. Both extraovarian (e.g. metabolic hormones) and intraovarian factors (e.g. growth factors) seem to be involved in mediating the effects of nutritional changes in follicle dynamics and oocyte quality (Boland et al. 2001). The original signal would be the change in glucose, which influences many reproductive hormones and factors (Rodríguez-lglesias et al. 1996) and increases folliculogenesis and ovulation rate (Scaramuzzi et al. 2006). Thus, a short-term infusion of glucose induces an immediate increase in leptin and insulin, which remained high during the period of treatment (Scaramuzzi et al. 2006). Insulin and leptin have become the focus of intense interest as potential metabolic signals directly regulating the ovary (Vinoles 2003, Munoz-Gutierrez 2005). Leptin has a reciprocal regulatory relation with ghrelin, a messenger coming directly from the gastrointestinal tract (Kalra et al. 2005). Nutrition is hypothesized to be regulated by cholecystokinin, leptin and insulin, decreasing food intake and ghrelin, and increasing food intake (Bronson 1998). Cholecystokinin and ghrelin regulate food intake in the short term, whereas leptin and insulin regulate food intake over longer periods (Gorissen et al. 2006). The interaction of these pathways may be masking the results of present and other different studies and make the development of further studies necessary.

In summary, the present results indicate that a shortterm nutritional supply with energy-yielding substrates (glucogenic mixtures) favours follicle development and increased ovulation rate. Such effects are mediated by the generation of a transitory positive energy balance that was not found to be related with changes in ghrelin secretion.

\section{Materials and Methods}

\section{Animals and experimental design}

A total of 16 Manchega sheep, 4-6 years old, were used. The ewes were maintained indoors with access to outdoor facilities at the experimental farm of the INIA Animal Reproduction Department in Madrid, Spain, latitude $40^{\circ} \mathrm{N}$; which meets the requirements of the European Union for Scientific Procedure Establishments. Sheep had free access to water. The basal diet consisted of $70 \%$ straw and $30 \%$ concentrate on dry matter basis, covering daily maintenance requirements. At the moment of feeding, the ewes were placed in individual pens. The diet was analysed for dry matter (DM) and metabolizable energy (ME) as previously described by Cundiff (1995), resulting in $88.7 \%$ DM and $3.00 \mathrm{Mcal} / \mathrm{kg}(12.55 \mathrm{MJ} / \mathrm{kg})$ for commercial pellets and $90.9 \% \mathrm{DM}$ and $2.10 \mathrm{Mcal} / \mathrm{kg}(8.79 \mathrm{MJ} / \mathrm{kg})$ for straw respectively. The nutritional necessities were calculated according to Agricultural and Food Research Council (AFRC) Manual (1993) for daily maintenance requirement $\left(M_{\mathrm{m}}\right)$ based on $\mathrm{ME}$ $\left(\left(M_{\mathrm{m}}(\mathrm{m} \mathrm{J} /\right.\right.$ day $\left.)\right)=(F+A) / \mathrm{K}_{\mathrm{m}}$, where $F$ is the fasting metabolism and $A$ the activity allowances). The experimental procedure was conducted at the end of June, during the transition from non-breeding to breeding season (Gomez-Brunet \& Lopez-Sebastian 1991); all the animals in the experimental group were cycling, as confirmed by detecting the presence of corpora lutea by ultrasound.

In all the animals, the oestrous cycle was synchronized with the insertion of one intravaginal progestagen-impregnated sponge (45 mg fluorogestone acetate, Chronogest; Intervet International, Boxmeer, The Netherlands), for 6 days (Ungerfeld \& Rubianes 1999, Knights et al. 2001), plus an i.m. injection of $125 \mu \mathrm{g}$ of a prostaglandin analogue (cloprostenol, Estrumate; Essex Animal Health, Friesoythe, Germany), at sponge insertion, for induction of luteolysis.

Two days after progestagen sponge insertion (day 0 of the experimental period), body condition (mean \pm S.E.M. of 4.05 \pm 0.06 ; 1 =emaciated, 5=obese; Farmnote 69, 1994, www.agric.wa.gov.au/aboutus/Pubns/farmnote_index.htm) and weight $(70.86 \pm 2.86 \mathrm{~kg})$ were determined in all the sheep. Half of the animals, irrespective of any parameter, were randomly allocated in one of two experimental groups. In the treated group, ewes received for 5 days (days 0-4) by the oral administration, twice daily, of $200 \mathrm{ml}$ of a glucogenic mixture. This formulation was adapted from Williams et al. (2001) and contained 70\% of glycerol (Panreac Quimica SA, Barcelona, Spain), 20\% of 1,2-propanediol (Panreac Quimica $\mathrm{SA})$ and $10 \%$ of water. The remaining animals received $200 \mathrm{ml}$ water, twice daily, acting as control group.

The effect of treatment on plasma glucose and ghrelin levels was assessed, from days 0 to 4 , in blood samples $(10 \mathrm{ml})$ drawn from jugular every $12 \mathrm{~h}$, coincidentally with the oral treatment. Samples were obtained using vacuum blood evacuation tubes containing heparin (Vacutainer Systems Europe, Becton Dickinson, Meylan Cedex, France). Immediately after recovery, blood samples were centrifuged at $1500 \mathrm{~g}$ for $15 \mathrm{~min}$, and plasma was removed and stored at $-20{ }^{\circ} \mathrm{C}$ until assayed. The ewes were again weighed and evaluated for body condition on the day after the end of 
Table 1 Body condition and weight ( \pm s.E.M.) in sheep that received a short-term energy input (GLU), just prior and after the treatment, and in ewes at maintenance levels (CONTROL), during the same period.

\begin{tabular}{|c|c|c|c|c|}
\hline & \multicolumn{2}{|c|}{ Body condition } & \multicolumn{2}{|c|}{ Body weight } \\
\hline & Day 0 & Day 5 & Day 0 & Day 5 \\
\hline CONTROL $(n=7)$ & $4.03 \pm 0.1$ & $4.03 \pm 0.1$ & $71.3 \pm 4.6$ & $71.8 \pm 4.9$ \\
\hline $\operatorname{GLU}(n=8)$ & $4.07 \pm 0.0$ & $4.07 \pm 0.1$ & $70.6 \pm 4.3$ & $70.5 \pm 4.0$ \\
\hline
\end{tabular}

glucogenic treatment (day 5). There were no significant changes in any variables (body weight and condition) when comparing days 0 and 5 (Table 1).

The effect of treatment on follicle dynamics and oestradiol secretion was evaluated by daily ultrasound scanning of the ovaries and determination of plasma oestradiol levels prior to the onset of oestrus behaviour. On day 4, coincidentally with the last treatment dose, the sponges were removed. Thereafter, detection of onset of heat behaviour was performed with trained rams, twice daily from $24 \mathrm{~h}$ after progestagen withdrawal.

\section{Assessment of follicles and corpora lutea by ultrasonography}

For determining the effect of glucogenic treatment on follicular population, the total number of follicles $\geq 2 \mathrm{~mm}$ in diameter present in both ovaries during the period of progestagen insertion and glucogenic supply (days -2 to 4 ) was considered. For determining effects on follicle dynamics during follicular phase, individual assessment of every $\geq 2 \mathrm{~mm}$ follicle was performed from progestagen withdrawal (day 4) to day of oestrus detection. For determining effects on ovulation rate, the number of corpora lutea was determined on day 9 after sponge removal.

Ovaries were examined by transrectal ultrasonography using a real-time, B-mode scanner (Aloka SSD 500; Aloka Co. Ltd, Tokyo, Japan) fitted to a $7.5 \mathrm{MHz}$ linear-array probe, as previously described and validated in our laboratory (Gonzalez-Bulnes et al. 1994). In every observation, each ovary was scanned several times from different angles in order to determine number, position and size of all $\geq 2 \mathrm{~mm}$ follicles or number of corpora lutea. During the follicular phase, the largest diameter of each of these follicles was measured and its position was recorded on a diagram of each ovary.

Ultrasonographic data were summarized to characterize patterns of follicular development. All follicles recorded by ultrasonography were classified by largest diameter for assessment of possible effects of time of treatment on the number of follicles of various size categories. Four groups were categorized: total follicles ( $\geq 2 \mathrm{~mm}$ in size), large $(\geq 6 \mathrm{~mm})$, medium (4-5 mm) and small follicles (2-3 mm). After this, during follicular phase, the number of new follicles (not previously detected), growing follicles (those that increased in size with respect to the previous day) and decreasing follicles (those that decreased in diameter with respect to the previous day or disappeared) were also considered. The size of the LF1 and the OF were recorded every day.

Nine days after sponge removal, the ovulation rate was assessed by counting the number of corpora lutea by ultrasonography; coincidentally, a blood sample was drawn as described above for assessing plasma progesterone and, thus, luteal function.

\section{Determination of glucose and hormones (ghrelin, oestradiol and progesterone)}

Glucose concentrations were measured using a Glucose RTU glucose meter (bioMeriuxSA, Marcy-l'Etoile, France). Sensitivity for glucose was $0.07 \mathrm{mmol} / \mathrm{l}$ and the inter- and intra-assay coefficients of variation were 3.0 and $2.0 \%$ respectively.

Plasma ghrelin concentrations were measured using Ghrelin RIA Kit (Phoenix Pharmaceuticals, Inc., Burlingame, CA, USA). This assay is specific for the first 11 AA of ghrelin, which are highly conserved among species, and detects 'total' ghrelin, including Ser3-octanoyl and Ser3-des-octanoyl ghrelins. Inter- and intraassay coefficients of variation were 10.5 and $13 \%$ respectively. The detectable range for the ghrelin assay was from 10 to $1280 \mathrm{pg} / \mathrm{ml}$ IC $_{50}$ in this assay system were $102.1 \mathrm{pg} / \mathrm{ml}$.

The concentration of peripheral oestradiol was measured using the Spectria RIA kit (Orion Diagnostic Corp., Espoo, Finland), as described by Romeu et al. (1995) and adapted for use in ovine plasma (Gonzalez-Bulnes et al. 2003). Sensitivity for oestradiol was $5 \mathrm{pmol} / \mathrm{l}$ and the inter- and intra-assay variation coefficients were 17.6 and $18.1 \%$ respectively.

Plasma progesterone concentrations were measured with a commercially available direct solid-phase RIA kit (Coat-A-Count; Diagnostic Products Co., Los Angeles, CA, USA). Sensitivity for progesterone was $0.03 \mathrm{ng} / \mathrm{ml}$ and the inter- and intra-assay variation coefficients were 4.0 and $3.6 \%$ respectively.

\section{Statistical analysis}

Evaluation of body weight at the beginning and end of the supplementation period was done by ANOVA and body condition score was done by Fisher's exact test. The effect of treatment on plasma concentrations of glucose and ghrelin, and on the number and size of follicles and characteristics of preovulatory follicles throughout the entire period of study was assessed by a split-plot ANOVA, followed by Kruskal-Wallis test, when Levene's test showed non-homogeneous variances, and by Pearson correlation analysis and linear regression procedures followed by Spearman non-parametric correlation tests where appropriate for non-homogeneous variables. Effect of treatment on oestradiol levels at oestrus, ovulation rate and plasma progesterone was estimated by the ANOVA. All results were expressed as the mean \pm S.E.M. and the statistical significance was accepted for $P<0.05$. 


\section{Acknowledgements}

First author is currently funded by a CONICYT (Chilean National Council of Science and Technology) doctoral fellowship. The authors declare that there is no conflict of interest that would prejudice the impartiality of this scientific work.

\section{References}

AFRC 1993 Requirements for metabolizable energy. In Energy and Protein Requeriments of Ruminants. An advisor manual prepared by the AFRC technical committee on responses to nutrients, pp 21-32. Wallingford. UK: CAB International.

Armstrong DG, Gong JG \& Webb R 2003 Interactions between nutrition and ovarian activity in cattle: physiological, cellular and mollecular mechanism. Reproduction Supplement 61 403-414.

Barreiro ML \& Tena-Sempere M 2004 Ghrelin and reproduction: a novel signal linking energy status and fertility? Molecular and Cellular Endocrinology 226 1-9.

Boland M, Lonergan P \& O'Callaghan D 2001 Effect of nutrition on endocrine parameters, ovarian physiology, and oocyte and embryo development. Theriogenology 55 1323-1340.

Bronson F 1998 Energy balance and ovulation: small cages versus natural habitats. Reproduction Fertility and Development 10 127-137.

Cundiff P 1995 Official Methods of Analysis, 16th edn. Arlington, VA: Association of Official Analytical Chemists (AOAC).

Cunningham MJ, Clifton DK \& Steiner RA 1999 Leptin's actions on the reproductive axis: perspectives and mechanisms. Biology of Reproduction $60216-222$.

Downing J, Joss J, Connell P \& Scaramuzzi RJ 1995 Ovulation rate and the concentrations of gonadotrophic and metabolic hormones in ewes fed lupin grain. Journal of Reproduction and Fertility 103 137-145.

Driancourt MA, Castonguay F, Bindon BM, Piper LR, Quirke JF \& Hanrahan JP 1990 Ovarian follicular dynamics in lines of sheep (Finn,Merinos) selected on ovulation rate. Journal of Animal Science 682034.

García MC, Lopez M, Alvarez CV, Casanueva F, Tena-Sempere M \& Diéguez C 2007 Role of ghrelin in reproduction. Reproduction 133 531-540.

Gaytan F, Barreiro ML, Chopin LK, Herington AC, Morales C, Pinilla L, Casanueva FF, Aguilar E, Diéguez C \& Tena-Sempere M 2003 Immunolocalization of ghrelin and its functional receptor, the type $1 \mathrm{a}$ growth hormone secretagogue receptor, in the cyclic human ovary. Journal of Clinical Endocrinology and Metabolism 88 879-887.

Gomez-Brunet A \& Lopez-Sebastian A 1991 Effect of season on plasma concentrations of prolactin and cortisol in pregnant, non-pregnant and lactating ewes. Animal Reproduction Science 26 251-268.

Gong JG 2002 Influence of metabolic hormones and nutrition on ovarian follicle development in cattle: practical implications. Reproduction in Domestic Animals 23 229-241.

Gonzalez-Anover P, Gonzalez-Bulnes A, Veiga-Lopez A, Garcia-Garcia RM, McNeilly AS \& Encinas T 2006 Effects of growth hormone and gonadotrophin releasing hormone antagonists on ovarian follicle growth in sheep. Journal of Veterinary Pharmacology and Therapeutics 29 373-377.

Gonzalez-Bulnes A, Santiago-Moreno J, Garcia-Lopez M, Gomez-Brunet A \& Lopez-Sebastian A 1994 Observación del ovario en la oveja y eficacia en la detección de folículos y cuerpos lúteos mediante ecografía transrectal. Investigación Agricola 10 319-329.

Gonzalez-Bulnes A, Garcia-Garcia RM, Castellanos V, Santiago-Moreno J, Ariznavarreta C, Domínguez V et al. 2003 Influence of maternal environment on the number of transferable embryos obtained in responset o superovulatory FSH treatments in ewes. Reproduction, Nutrition, Development 43 17-28.

Gorissen MHAG, Flik G \& Huising MO 2006 Peptides and proteins regulating food intake: a comparative view. Animal Biology 56 447-473.

Gutierrez C, Oldhman J, Bramley T, Gong J, Campbell B \& Webb R 1997 The recruitment of ovarian follicles is enhanced by increased dietary intake in heifers. Journal of Animal Science 75 1876-1884.
Harrison J, Adam C, Brown Y, Wallace J, Aitken R, Lea R \& Miller D 2007 An immunohistochemical study of the localization and developmental expression of ghrelin and its functional receptor in the ovine placenta. Reproduction Biology and Endocrinology 5 477-485.

Hayashida T 2001 Ghrelin in domestic animals: distribution in stomach and its possible role. Domestic Animal Endocrinology 21 17-24.

Hess BW, Lake SL, Scholljegerdes EJ, Weston TR, Nayigihugu V, Molle JD \& Moss GE 2005 Nutritional controls of beef cow reproduction. Journal of Animal Science 83 90-106.

Hinch G \& Roelofs J 1986 Lupin feeding and insulin infusion during the late luteal phase can increase ovulation rate in sheep. Proceedings of the Australian Society for Reproductive Biology 1843.

Kalra SP, Ueno N \& Kalra PS 2005 Stimulation of appetite by ghrelin is regulated by leptin restraint: peripheral and central sites of action. Journal of Nutrition 135 1331-1335.

Knights M, Maze TD, Bridges PJ, Lewis PE \& Inskeep EK 2001 Short-term treatment with a controlled internal drug releasing (CIDR) device and $\mathrm{FSH}$ to induce fertile estrus and increase prolificacy in anestrous ewes. Theriogenology 55 1181-1191.

Landau S, Bor A, Leibovich H, Zoref Z, Nistan Z \& Madar Z 1995 The effect of ruminal starch degradability in the diet of booroola crossbred ewes on induced ovulation rate and prolifacy. Animal Reproduction Science $\mathbf{3 8}$ 97-108.

Landau S, Houghton JA, Mawhinney JR \& Inskeep EK 1996 Protein sources affect follicular dynamics in ewes near the onset of the breeding season. Reproduction Fertility and Development 8 1021-1028.

Letelier C, Gonzalez-Bulnes A, Hervé M, Correa J \& Pulido R 2008 Enhancement of ovulatory follicle development in maiden sheep by short-term supplementation with steam-flaked corn. Reproduction in Domestic Animals 43 222-227.

Lindsay D, Martin GB \& Williams I 1993 Nutrition and reproduction. In Reproduction in Domesticated Animals: World Animal Sciences Series, pp 459-491. Ed. GJ King. Amsterdam: Elsevier Science Publishers.

Marie M, Findlay PA, Thomas L \& Adam CL 2001 Daily patterns of plasma leptin in sheep: effects of photoperiod and food intake. Journal of Endocrinology 170 277-286.

Martin GB, Rodger J \& Blache D 2004 Nutritional and environmental effects on reproduction in small ruminants. Reproduction Fertility and Development 16 491-501.

Miller D, Harrison J, Brown Y, Doyle U, Lindsay A, Adam C \& Lea R 2005 Immunohistochemical evidence for an endocrine/paracrine role for ghrelin in the reproductive tissues of sheep. Reproduction Biology and Endocrinology 3 1-18.

Munoz-Gutiérrez M 2005 The effect of glucose and leptin on folliculogenesis in the ewe. Docotoral Thesis Perth: University of London, UK.

Munoz-Gutiérrez M, Blache D, Martin GB \& Scaramuzzi RJ 2002 Folliculogenesis and ovarian expression of $\mathrm{mRNA}$ encoding aromatase in anoestrous sheep after 5 days of glucose or glucosamine infusion or supplementary lupin feeding. Reproduction 124 721-731.

Munoz-Gutiérrez M, Blache D, Martin GB \& Scaramuzzi RJ 2004 Ovarian follicular expression of mRNA encoding the type I insulin like growth factor receptor (IGF-IR) and insulin like growth factor binding protein 2 (IGFBP2) in anoestrus sheep after 5 days of glucose or glucosamine or supplementary feeding with lupin grain. Reproduction 128 1-11.

O'Callaghan D, Yaakub H, Hyttel P, Spicer L \& Boland MP 2000 Effect of nutrition and superovulation on oocyte morphology, follicular fluid composition and systemic hormone concentrations in ewes. Journal of Reproduction and Fertility 118 303-313.

Pearse BH, Mcmeniman NP \& Gardner IA 1994 Influence of body condition on ovulatory response to lupin (Lupinus angustifolius) supplementation of sheep. Small Ruminant Research 13 27-32.

Rodríguez-Iglesias RM, Ciccioli NH, Irazoqui H \& Giglioli C 1996 Ovulation rate in ewes after single oral glucogenic dosage during a ram-induced follicular phase. Animal Reproduction Science 44 211-221.

Romeu A, Molina I, Tresguerres JA, Pla M \& Peinado JA 1995 Effect of recombinant human luteinizing hormone versus human chorionic gonadotrophin: effects on ovulation, embryo quality and transport, steroid balance and implantation in rabbits. Human Reproduction $\mathbf{1 0}$ 1290-1296.

Rowe JB \& Ferguson J 1986 Lupin grain as a supplement for sheep grazing cereal stubble. Proceeding of the Australian Society of Animal Production 16 343-346. 
Rubio JM, Hallford DM \& Hawkins DE 1997 Effect of glucose administration during the estrous cycle on serum hormone profiles, mRNA for steroidogenic enzymes, and breeding performance of ewes. Journal of Animal Science 75 775-780.

Scaramuzzi RJ, Adams NR, Baird DT, Campbell BK, Downing JA, Findlay JK, Henderson KM, Martin GB, McNatty KP, McNeilly AS et al. 1993 A model for follicle selection and the determination of ovulation rate in the ewe. Reproduction Fertility and Development 5 459-478.

Scaramuzzi R, Campbell B, Downing J, Kendall N, Khalid M, MunozGutierrez M \& Somchit A 2006 A review of the effects of supplementary nutrition in the ewe on the concentrations of reproductive and metabolic hormones and the mechanisms that regulate folliculogenesis and ovulation rate. Reproduction, Nutrition, Development 46 339-354.

Smith A \& Stewart R 1990 Effects of nutrition on the ovulation rate of ewes. In: Reproductive Physiology of Merino Sheep: Concepts and Consequences. Eds CM Oldham, GB Martin, IW Martin \& I Purvis. Perth: School of Agriculture, University of Western Australia.

Spicer LJ 2001 Leptin: a possible metabolic signal affecting reproduction. Domestic Animal Endocrinology 21 251-270.

Stewart R 1990 The effect of nutrition on the ovulation rate of the ewe. $P h D$ Thesis, p 206. Perth: Department of Animal Science, University of Western Australia.

Stewart R \& Oldham C 1986 Feeding lupins to ewes for four days during the luteal phase can increase ovulation rate. Proceedings of the Australian Society of Animal Production 16 367-370.

Sugino T, Hasegawa Y, Kurose Y, Kojima M, Kangawa K \& Terashima Y 2004 Effects of ghrelin on food intake and neuroendocrine function in sheep. Animal Reproduction Science 82-83 183-194.

Takahashi H, Kurose Y, Kobayashi S, Sugino T, Kojima M, Kangawa K, Hasegawa Y \& Terashima Y 2006 Ghrelin enhances glucose-induced insulin secretion in scheduled meal-fed sheep. Journal of Endocrinology $18967-75$.

Teleni E, Rowe J, Croker K, Murray P \& King W 1989 Lupins and energyyielding nutrients in ewes. II. Responses in ovulation rate in ewes to increased availability of glucose, acetate and amino acids. Reproduction Fertility and Development 117-125.

Tena-Sempere M 2005 Exploring the role of ghrelin as novel regulator of gonadal function. Growth Hormone and IGF Research 15 83-88.
Truett GE \& Parks EJ 2005 Ghrelin: its role in energy balance. Journal of Nutrition 1351313.

Ungerfeld R \& Rubianes E 1999 Effectiveness of short-term progestogen primings for the induction of fertile estrus with eCG in ewes during late seasonal anestrus. Animal Science 68 349-353.

Vinoles C 2003. Effect of nutrition on follicle development and ovulation rate in the ewe. Doctoral Thesis Perth: Swedish University of Agricultural Sciences.

Vinoles C, Meikle A, Forsberg M \& Rubianes E 1999 The effect of subluteal levels of exogenous progesterone on follicular dynamics and endocrine patterns during early luteal phase of the ewe. Theriogenology $\mathbf{5 1}$ 1351-1361.

Vinoles C, Meikle A, Banchero G \& Rubianes E 2002 Ovarian follicular dynamics and endocrine profiles in Polwarth ewes with high and low body condition. Animal Science 74 539-545.

Vinoles C, Forsberg M, Martin GB, Cajarville C, Repetto J \& Meikle A 2005 Short-term nutritional supplementation of ewes in low body condition affects follicle development due to an increase in glucose and metabolic hormones. Reproduction 129 299-309.

Webb R, Garnsworthy PC, Gong JG \& Armstrong DG 2004 Control of follicular growth: local interactions and nutritional influences. Journal of Animal Science 82 63-74.

Wertz-Lutz AE, Knight TJ, Pritchard RH, Daniel JA, Clapper JA, Smart AJ, Trenkle A \& Beitz DC 2006 Circulating ghrelin concentrations fluctuate relative to nutritional status and influence feeding behavior in cattle. Journal of Animal Science 84 3285-3300.

Williams SA, Blache D, Martin GB, Foot R, Blackberry MA \& Scaramuzzi RJ 2001 Effect of nutritional supplementation on quantities of glucose transporters 1 and 4 in sheep granulosa and theca cells. Reproduction 122 947-956.

Received 7 January 2008

First decision 12 February 2008

Accepted 3 April 2008 